\title{
Factors affecting mortality in children requiring continuous renal replacement therapy in pediatric intensive care unit
}

\author{
Monika Miklaszewska ${ }^{1, A-D}$, Przemysław Korohoda ${ }^{2, C, D}$, Katarzyna Zachwieja ${ }^{1, B, E}$, Alina Sobczak ${ }^{3, B}$, \\ Krzysztof Kobylarz', ${ }^{4}$, Constantinos J. Stefanidis ${ }^{5, E, F}$, Jolanta Goździk ${ }^{6, B}$, Dorota Drożdż', ${ }^{1}, F$ \\ 1 Department of Pediatric Nephrology and Hypertension, Jagiellonian University Medical College, Kraków, Poland \\ 2 Department of Electronics, Faculty of Computer Science, Electronics and Telecommunications, AGH University of Science and Technology, Kraków, Poland \\ ${ }^{3}$ Department of Pediatrics, Faculty of Medicine, Jagiellonian University Medical College, Kraków, Poland \\ ${ }^{4}$ Department of Anesthesiology and Intensive Care, Institute of Pediatrics, Jagiellonian University Medical College, Kraków, Poland \\ ${ }^{5}$ Department of Pediatric Nephrology, A. and P. Kyriakou Children's Hospital, Athens, Greece \\ ${ }^{6}$ Department of Transplantology, Division of Clinical Immunology and Transplantation, Jagiellonian University Medical College, Kraków, Poland \\ A - research concept and design; B - collection and/or assembly of data; $\mathrm{C}$ - data analysis and interpretation; \\ $\mathrm{D}$ - writing the article; $\mathrm{E}$ - critical revision of the article; $\mathrm{F}$ - final approval of the article
}

Address for correspondence

Monika Miklaszewska

E-mail:mmiklasz@wp.pl

Funding sources

None declared

Conflict of interest

None declared

Received on June 16, 2017

Reviewed on 0ctober 19, 2017

Accepted on December 7, 2017

Published online on November 21, 2018

Cite as

Miklaszewska M, Korohoda P, Zachwieja K, et al. Factors affecting mortality in children requiring continuous renal replacement therapy in pediatric intensive care unit. Adv Clin Exp Med. 2019;28(5):615-623. doi:10.17219/acem/81051

DOI

10.17219/acem/81051

Copyright

Copyright by Author(s)

This is an article distributed under the terms of the

Creative Commons Attribution Non-Commercial License

(http://creativecommons.org/licenses/by-nc-nd/4.0/)

\section{Abstract}

Background. Acute kidney injury (AKI) occurs in up to 30\% of pediatric intensive care unit (PICU) patients and is associated with a high mortality rate.

Objectives. The objective of the study was to evaluate factors associated with the outcome and to identify the prognostic factors in children receiving continuous renal replacement therapy (CRRT).

Material and methods. This was a retrospective, single-center study, including 46 patients.

Results. Logistic regression analysis demonstrated significant effects on patient survival exerted by the percentage of fluid overload (FO\%) (odds ratio (OR): 1.030; $p=0.044$ ). In the group of patients with $\mathrm{F} 0 \%<25 \%$, the mortality was $33.3 \%$, and in the $\mathrm{F} 0 \% \geq 25 \%$ group, the mortality was $67.9 \%(p<0.001)$. The probability of death without multi-organ failure (MOF) was 13\%, while with MOF it was 74\%. There was no difference in the duration of hospitalization between the CRRT patients (mean: 21.9 days) and the general population of children hospitalized in PICU in the same period ( $n=3,255$; mean: 25.4 days); however, a significant difference was noted in mortality between the 2 groups of patients ( $54 \%$ vs $6.5 \% ; p<0.001$ ).

Conclusions. The mortality of PICU CRRT patients is more than 8-fold higher than the mortality of the total PICU population. Coexisting MOF increases the mortality almost 6 times. The mortality of children with $\mathrm{F} 0 \% \geq 25 \%$ was more than 2-fold higher than the mortality of children with $\mathrm{F} 0 \%<25 \%$.

Key words: acute kidney injury, survival, anticoagulation, pediatric intensive care unit, continuous renal replacement therapy 


\section{Introduction}

Acute kidney injury (AKI) is observed in up to $30 \%$ of children admitted to pediatric intensive care units (PICUs) and is associated with a mortality rate of up to $50 \% \cdot{ }^{1-3}$ There is evidence that the epidemiology of pediatric AKI has changed over the past few decades and that primary renal diseases are currently no longer the most common causes of AKI. ${ }^{4}$ Nowadays, the most frequent causes of AKI in developed countries are acute tubular necrosis, nephrotoxic medications, oncological diseases, septic shock, and their common consequence - multi-organ-failure (MOF). ${ }^{5}$ Over the past 2 decades, in many developed countries, continuous renal replacement therapy (CRRT) has become the most widely used renal support modality in critically ill children. ${ }^{6}$ It eliminates the need for fluid restriction and allows for the provision of medications, blood products and nutrition in critically ill children. ${ }^{7}$

Despite the increasing use of CRRT, AKI is associated with an increased risk of mortality in critically ill patients. ${ }^{8,9}$ Although formal and clearly defined indications for CRRT use are lacking, it is mostly employed for individual AKI and AKI associated with fluid overload (FO), MOF and sepsis. ${ }^{10}$ Furthermore, there are still not many published reports addressing CRRT in PICUs. ${ }^{6}$

The main objective of the present study was to evaluate the clinical course, to analyze factors associated with the outcome and to identify prognostic factors in critically ill children receiving CRRT.

\section{Material and methods}

This was a retrospective, single-center, chart review study, including 46 patients receiving CRRT, who had been admitted to the PICU in the Department of Anesthesiology and Intensive Care, Institute of Pediatrics, Jagiellonian University Medical College, Kraków, Poland, between January 2009 and December 2016. This study was approved by the Bioethical Committee of Cracow Medical Chamber (OIL/KBL/4/2017).

Initiation, prescription and general CRRT management occurred under the guidance of the attending intensivist and consulting nephrologist. The primary indications for the initiation of CRRT were categorized as AKI, FO or MOF. Fluid overload percentage (FO\%) was determined using the PICU admission weight in kilograms as the baseline weight for comparison. The FO\% was defined using the method described by Goldstein et al. ([fluid in - fluid out]/[intensive care unit admission weight] $\times 100 \%$ ), and fluid in (or out) was considered to be the amount of fluid from admission to PICU to CRRT initiation. ${ }^{11}$ Acute kidney injury was determined by the pediatric-modified Risk, Injury, Failure, Loss of kidney function, and End-stage kidney disease score (RIFLE, modified into p-RIFLE). ${ }^{2}$ Multi-organ failure was defined as the presence of at least 2 organs involved at any time on admission to PICU.12 Sepsis was defined using the criteria of the International Consensus Conference on Pediatric Sepsis. ${ }^{12}$

A Prismaflex dialysis machine (Gambro, Barcelona, Spain) was used for CRRT in all the patients. Dual lumen catheters were used depending on the age, weight and morphology of the child, using the same criteria for the patients treated with regional citrate anticoagulation (RCA) and heparin anticoagulation (Hep-ACG) ${ }^{8,13} \mathrm{Hol}-$ low fiber hemofilters were used depending on the body weight of the patient, according to the guidelines of the manufacturer. ${ }^{14}$

In all the Hep-ACG cases, predilutional continuous veno-venous hemodiafiltration (CVVHDF) was employed and unfractionated heparin (Hep) was used. In the Hep-ACG protocol, a Hep bolus was administered during the connection along with a subsequent continuous Hep infusion to achieve a post-filter activated clotting time (ACT) between 180 and $240 \mathrm{~s}$. The ACT value was checked on average every $2 \mathrm{~h}$ within the first $12 \mathrm{~h}$ of CRRT, and then every 4-6 h.

The RCA procedure was conducted according to the guidelines from the study by Tolwani et al. and from the Prismaflex operator's manual. ${ }^{14,15}$ An initial citrate concentration of $3.0 \mathrm{mmol} / \mathrm{L}$ was used for a target post-filter ionized calcium level of $0.25-0.50 \mathrm{mmol} / \mathrm{L}$. The citrate effect was neutralized using a continuous calcium infusion of $10 \%$ calcium gluconate (or $5 \%$ in children weighing $<15 \mathrm{~kg}$ ) to maintain ionized calcium blood levels between 1.0 and $1.2 \mathrm{mmol} / \mathrm{L} .{ }^{15,16}$ Samples were taken every hour for the first $4 \mathrm{~h}$ and every $6-8 \mathrm{~h}$ afterwards. Total calcium levels were also checked at least once daily. Citrate accumulation was avoided by monitoring the patient's $\mathrm{pH}$ status and by total calcium/ionic calcium index (CaT/CaI) being maintained $\leq 2.5$.

Regarding the CRRT solutions for Hep-ACG, Hemosol, or PrismaSol 2 (Gambro) as a dialyzate and Phoxilium (Gambro) or PrismaSol 2 as a predilutional substitute were used; whereas for RCA, the citrate solution Prismocitrate 18/0 (Gambro) was administered in a pre-blood pump (PBP), the dialyzate normocarbonate solution PrismOcal B22 (Gambro) was used as a calcium-free dialysis solution, and the low-flow post-filter infusion of PrismaSol 2 or Phoxillum was employed as a postdilutional substitute to avoid clotting in the deaeration chamber return line.

In both techniques, the dialyzate and substitution flow rates were initially programmed to achieve a dialysis dose of at least $35 \mathrm{~mL} / \mathrm{kg} / \mathrm{h}$ and were subsequently adjusted in an ongoing manner to meet the patients' needs. None of the filters were used for longer than $72 \mathrm{~h}$. The blood flow rates (BFR) were determined according to the patients' body mass and were monitored by the pressure at the access sites. ${ }^{15}$

Dual lumen catheters were individually adapted to the child's morphology and body weight according to the literature recommendations. ${ }^{8,13}$ The implantation sites of the 
dual lumen catheters included the left femoral vein in 19 cases (41.3\%), the right femoral vein in 13 cases $(28.3 \%)$ and the right internal jugular vein in 14 cases (30.4\%).

The collected data addressed the patients' demographics, underlying disease, detailed CRRT parameters, and the mode and dose of the applied anticoagulation (ACG) method.

\section{Statistical analysis}

The distribution of polytomous variables was described employing the mean value, standard deviation (SD), median value, and interquartile range (IQR). To compare the distributions, Student's t-test was used, providing the Kolmogorov-Smirnov (KS) test yielded a positive result for conformity of the empirical distribution and Gaussian distribution. In case of a lack of such conformity, the Wilcoxon rank-sum test (equivalent to the Mann-Whitney U test) was employed; this fact was indicated by marking the appropriate p-value with an asterisk (*). The sample sizes were compared by means of the $X^{2}$ test; in the cases with low predicted frequencies, Yates's modification was employed, which was indicated by marking the appropriate p-values with 2 asterisks $(* *)$. The effect of FO\% on the cumulative survival probability of the patients was analyzed employing the Kaplan-Meier curves and the Mantel-Cox test. Additionally, the univariate and multivariate analyses of significant parameters were carried out depending on ACG and the outcome. In addition, the univariable and multivariable logistic regression analyses were performed, identifying the parameters showing a significant odds ratio (OR) and describing the effect on the outcome. When only dichotomous input variables were considered, the OR was computed directly from the contingency table analysis. It should be emphasized that depending on the employed mode of analysis, the numerical assessment of the effect of a given parameter on the outcome was achieved in the form of probability of death (mortality) or OR of death (mortality OR). In all tests, the significance threshold was assumed to be 0.05 , with the exception of the KS test, where a value of 0.1 was assumed to be significant. The STATISTICA v. 12 (StatSoft Inc., Tulsa, USA) and MATLAB v. 2015a (Mathworks, Natick, USA) packages were used for all calculations and for creating the graphs.

\section{Results}

The number of children requiring CRRT in particular years was as follows: in $2009-6$ patients; $2010-3 ; 2011$ - 7; 2012 - 4; 2013 - 6; 2014-5; 2015 - 5; and in 2016 - 10 . As RCA has been used in our center since 2015, 4 patients in 2015 and 10 patients in 2016 were treated with this mode of ACG. The Hep-ACG was applied in all other cases.

A detailed characteristics of the study population is included in Tables 1 and 2. The main diagnoses in the studied population were as follows: 1 . oncological diseases - 20 children (43.5\%), including acute lymphoblastic leukemia - 11 (8 after bone marrow transplantation (BMT)), lymphoma -3 , solid tumors -3 , and acute myeloid leukemia after BMT -3 ; 2 . hematological diseases -6 children (13\%), including aplastic anemia after BMT - 3, severe combined immunodeficiency after BMT - 2 and hemophagocytic syndromes after BMT - 1; 3. nephrological diseases - 11 children (24\%), including chronic kidney disease (CKD) exacerbation - 4, chronic dialysis complications -3 , rapid progressive glomerulonephritis -1 , hemolytic uremic syndrome -2 , and tubulointerstitial nephritis - 1; 4 . sepsis - 3 children (6.5\%), including Neisseria meningitidis -2 and Streptococcus spp. -1 ; 5 . burns -2 children (4.3\%); 6 . cardiovascular diseases -2 children (4.3\%); 7. rheumatic disease (systemic lupus erythematosus) - 1 child (2.2\%); and 8. gastroenterological diseases -1 child (2.2\%).

There were no statistically significant differences in the ratio of the main diagnoses, neither between Hep-ACG and RCA, nor between deceased and surviving patients (apart from nephrological diagnoses in the case of deceased vs surviving patients: 1 vs $10 ; \mathrm{p}=0.001$ ).

While comparing the sample size in children dialyzed with Hep-ACG vs RCA, no statistically significant differences were noted in gender, body mass, body height, or outcome, which means that the studied populations were mutually equivalent and relevantly representative for the current study. The patients treated with RCA demonstrated longer hospitalization in PICU, were younger, and, in view of the additional citrate flow, they received a higher dialysis dose in total than the children treated with HepACG. In turn, when compared to the RCA group, the children treated with Hep-ACG were characterized by a more severe clinical status (which was evident in a higher number of vasopressor medications (VPS) at CRRT initiation and a higher absolute percentage of days with VPS administration during their PICU stay), required mechanical ventilatory support extending over a longer proportion of their PICU hospitalization and their urine output (UO) at the time of CRRT initiation was lower.

As shown in Tables 2 and 3, 46\% of the patients from the study population survived. There were no significant differences between the survivors and non-survivors with respect to age, weight, height, gender, number of days spent in PICU, estimated glomerular filtration rate (eGFR) value, urea concentration, total protein, albumin concentration at the start of CRRT, day of CRRT initiation, number of hours of CRRT per patient, dialysis dose per patient, ultrafiltration rate (UFR) value per patient, or ACT value.

On the other hand, as shown in Table 2, the surviving children were subjected to CRRT mainly for AKI or FO\% (as the immediate causes of CRRT initiation), required less intensive mechanical ventilatory support during their hospitalization in PICU, had fewer VPS at CRRT initiation, 
Table 1. Clinical characteristics of children treated with heparin anticoagulation (Hep-ACG) and regional citrate anticoagulation (RCA)

\begin{tabular}{|c|c|c|c|c|}
\hline Variable & $\begin{array}{c}\text { Hep-ACG, } n=32(69.6 \%) \\
n[\%]\end{array}$ & $\begin{array}{c}\mathrm{RCA}, \mathrm{n}=14(30.4 \%) \\
\mathrm{n}[\%]\end{array}$ & p-value & $\begin{array}{l}\text { Total, } \mathrm{n}=46 \\
\mathrm{n}[\%]\end{array}$ \\
\hline Surviving/deceased & $12(37.5) / 20(62.5)$ & $9(64.3) / 5(35.7)$ & NS & $21(45.6) / 25(54.5)$ \\
\hline Males/females & $16 / 16$ & $11 / 3$ & NS & $27 / 19$ \\
\hline $\begin{array}{l}\text { Patients with MOF as the main reason for CRRT } \\
\text { implementation }\end{array}$ & 24 & 7 & $N S^{* *}$ & 31 \\
\hline $\begin{array}{l}\text { Patients with } \mathrm{AKI} \text { as the main reason for CRRT } \\
\text { implementation }\end{array}$ & 5 & 2 & $N S^{* *}$ & 7 \\
\hline $\begin{array}{l}\text { Patients with } \mathrm{FO} \% \text { as the main reason for CRRT } \\
\text { implementation }\end{array}$ & 3 & 5 & $N S^{* *}$ & 8 \\
\hline $\begin{array}{l}\text { Patients with mechanical ventilation at CRRT } \\
\text { initiation }\end{array}$ & 27 (84.4) & $8(57.1)$ & $\mathrm{NS}^{* *}$ & 35 (76.1) \\
\hline Days with VPS administration during PICU stay & $406(81.5)$ & $273(53.4)$ & $<0.001$ & $679(67.3)$ \\
\hline Days with diuretic administration during PICU stay & $336(67.5)$ & $282(55.2)$ & $<0.001$ & $618(61.2)$ \\
\hline CRRT sessions, clotted/non-clotted & $27(24.1) / 85(75.9)$ & $34(31.5) / 74(68.5)$ & NS & $61(27.7) / 159(72.3)$ \\
\hline $\begin{array}{l}\text { Number of hours of CRRT sessions, } \\
\text { clotted/non-clotted }\end{array}$ & $\begin{array}{l}516(10) / 4,666(90) \\
5,182(48.6)\end{array}$ & $\begin{array}{c}882(16.1) / 4,599(83.9) \\
5,481(51.4)\end{array}$ & $<0.001$ & $\begin{array}{c}1,398(13.1) / 9,265(86.9) \\
10,663\end{array}$ \\
\hline Variable & mean $\pm \mathrm{SD} /$ median $(\mathrm{IQR})$ & mean $\pm \mathrm{SD} /$ median $(\mathrm{IQR})$ & $\mathrm{p}$-value & mean \pm SD/median (IQR) \\
\hline Age [years] & $10.5 \pm 5.4 / 11.7(10.2)$ & $6.7 \pm 6.8 / 3.8(12.8)$ & 0.046 & $9.3 \pm 6.0 / 10.3(11.4)$ \\
\hline Body mass [kg] & $36.3 \pm 20.3 / 31.5(31.6)$ & $26.8 \pm 22.6 / 16.3(35.6)$ & NS & $33.4 \pm 21.2 / 29.5(34.6)$ \\
\hline Body height $[\mathrm{cm}]$ & $133.9 \pm 31.0 / 137.0(58.5)$ & $111.6 \pm 43.6 / 108.5(84.0)$ & NS & $127.1 \pm 36.4 / 134.5(67.0)$ \\
\hline Number of days in PICU/patient & $15.6 \pm 12.2 / 12.5(17.0)$ & $36.5 \pm 26.1 / 32.5(52.0)$ & 0.001 & $21.9 \pm 19.9 / 17.5(27.0)$ \\
\hline Percentage of days of mechanical ventilation & $77.7 \pm 37.1 / 100.0(40.0)$ & $49.3 \pm 43.1 / 58.5(100.0)$ & $0.021^{*}$ & $69.0 \pm 40.7 / 100.0(68.0)$ \\
\hline Number of VPS at CRRT initiation & $1.34 \pm 0.90 / 1.00(1.00)$ & $0.71 \pm 0.73 / 1.00(1.00)$ & 0.026 & $1.15 \pm 0.89 / 1.00(2.00)$ \\
\hline CRP $[\mathrm{mg} / \mathrm{L}]$ at CRRT initiation & $189 \pm 144 / 187(229)$ & $132 \pm 110 / 116(149)$ & NS & $172 \pm 136 / 151(215)$ \\
\hline Total protein $[\mathrm{g} / \mathrm{L}]$ at CRRT initiation & $51.4 \pm 10.7 / 51.5(14.1)$ & $54.5 \pm 12.5 / 56.2(9.7)$ & NS & $52.4 \pm 11.2 / 53.1(15.1)$ \\
\hline Albumin [g/L] at CRRT initiation & $26.6 \pm 5.9 / 26.0(7.8)$ & $31.3 \pm 9.6 / 33.4(10.1)$ & NS & $28.1 \pm 7.4 / 28.0(11.2)$ \\
\hline eGFR $\left[\mathrm{mL} / \mathrm{min} / 1.73 \mathrm{~m}^{2}\right]$ at CRRT initiation & $37.1 \pm 23.9 / 33.2(27.9)$ & $42.4 \pm 21.6 / 44.3(29.1)$ & NS & $38.7 \pm 23.1 / 34.7(32.7)$ \\
\hline Urea [mmol/L] at CRRT initiation & $25.1 \pm 14.4 / 25.2(24.0)$ & $21.5 \pm 16.7 / 16.1(8.8)$ & NS & $24.0 \pm 15.0 / 20.1(20.4)$ \\
\hline $\mathrm{UO}[\mathrm{mL} / \mathrm{kg} / \mathrm{h}]$ at CRRT initiation & $0.75 \pm 0.71 / 0.45(1.25)$ & $1.54 \pm 1.41 / 1.10(2.10)$ & 0.014 & $0.99 \pm 1.03 / 0.65(1.30)$ \\
\hline FO\% at CRRT initiation & $36.7 \pm 32.8 / 26.0(32.8)$ & $32.6 \pm 29.7 / 29.8(30.0)$ & NS & $35.5 \pm 31.6 / 27.3(32.5)$ \\
\hline Day of CRRT initiation & $5.2 \pm 5.3 / 2.5(8.0)$ & $6.8 \pm 9.9 / 1.5(5.0)$ & $N S^{*}$ & $5.7 \pm 6.9 / 2.0(8.0)$ \\
\hline Dialysis dose: QD+QS (+QC) [mL/h/kg]/patient & $50.7 \pm 16.0 / 48.0(18.6)$ & $68.2 \pm 26.4 / 63.6(35.7)$ & $<0.001^{*}$ & $59.6 \pm 23.6 / 55.0(31.9)$ \\
\hline
\end{tabular}

* Wilcoxon rank-sum test; ${ }^{*}$ Yates's modification of the $x^{2}$ test; AKI - acute kidney injury; CRP - C-reactive protein; CRRT - continuous renal replacement therapy; eGFR - estimated glomerular filtration rate; FO\% - fluid overload percentage; Hep-ACG - heparin anticoagulation; MOF - multi-organ failure; PICU - pediatric intensive care unit; QC - citrate flow rate; QD - dialyzate flow rate; QS - supplement flow rate; RCA - regional citrate anticoagulation; UO - urine output; VPS - vasopressors; SD - standard deviation; IQR - interquartile range; NS - not significant.

had a lower absolute percentage of days with VPS administration during their PICU stay, and had lower values of inflammatory marker (C-reactive protein (CRP)), but they maintained a significantly higher diuresis value at the time of CRRT initiation, which resulted in their mean degree of overhydration being 1.9 times lower on average. If the positive blood culture was not associated with sepsis, or with AKI and/or FO\%, it also did not affect mortality in these patients. The only factor that was associated with a lower mortality was nephrological primary disease. Multi-organ failure occurred in 92\% of the deceased children and it proved that the probability of death without MOF amounted to $13 \%$, while the probability of death with MOF was 74\%, thus being 5.7 times higher (mortality OR: 18.7; $\mathrm{p}<0.001)$.
As shown in Table 2, FO\% showed significant differences between the surviving and deceased children. In the group of children with FO\% $<25 \%(\mathrm{n}=18)$, mortality amounted to $33.3 \%(n=6)$, while in the group of children with FO $225 \%$ ( $n=28)$, mortality was more than 2-fold higher, amounting to $67.9 \%(\mathrm{n}=19, \mathrm{p}<0.001)$. Also, the analysis of the Kaplan-Meier curves (Fig. 1) showed that the survival outcomes worsened with $\mathrm{FO} \% \geq 25 \%$ at CRRT initiation.

The univariable logistic regression analysis demonstrated that significant effects on patient survival were exerted byFO\%(OR: 1.030; confidence interval(CI) 95\%: 1.001-1.059; $\mathrm{p}=0.044$ ), CRP value at CRRT initiation (OR: 1.078; CI 95\%: 1.019-1.142; $\mathrm{p}=0.009$ ) and percentage of days with mechanical ventilatory support (OR: 1.068; CI 95\%: $1.026-1.112 ; \mathrm{p}=0.001)$. This denoted that each $1 \%$ increase 
Table 2. Univariate analysis of clinical factors associated with mortality in the studied population

\begin{tabular}{|c|c|c|c|c|}
\hline Variable & $\begin{array}{c}\text { Deceased, } \mathrm{n}=25(54 \%) \\
\mathrm{n}[\%]\end{array}$ & $\begin{array}{c}\text { Surviving, } \mathrm{n}=21(46 \%) \\
\mathrm{n}[\%]\end{array}$ & $\mathrm{p}$-value & $\begin{array}{c}\text { Total, } n=46 \\
n[\%]\end{array}$ \\
\hline Males/females & $15 / 10$ & $12 / 9$ & NS & $27 / 19$ \\
\hline Main reason of CRRT initiation - MOF & 23 & 8 & $<0.001$ & 31 \\
\hline Main reason of CRRT initiation - AKI & 0 & 7 & $0.006^{* *}$ & 7 \\
\hline Main reason of CRRT initiation - FO\% & 0 & 8 & $0.003^{* *}$ & 8 \\
\hline $\begin{array}{l}\text { Patients with mechanical ventilation } \\
\text { - SIMV }\end{array}$ & 20 & 9 & 0.009 & 29 \\
\hline $\begin{array}{l}\text { Patients with mechanical ventilation } \\
\text { - oscillation }\end{array}$ & 5 & 3 & $N S^{* *}$ & 8 \\
\hline $\begin{array}{l}\text { Patients intubated on the day of CRRT } \\
\text { initiation }\end{array}$ & 24 & 11 & $<0.001$ & 33 \\
\hline $\begin{array}{l}\text { Patients with positive blood culture } \\
\text { during PICU stay }\end{array}$ & 12 & 5 & NS & 17 \\
\hline $\begin{array}{l}\text { Patients on diuretics on the day of CRRT } \\
\text { initiation }\end{array}$ & 19 & 14 & NS & 33 \\
\hline $\begin{array}{l}\text { Days with VPS administration during } \\
\text { PICU stay }\end{array}$ & $425(83.3)$ & $254(50.9)$ & $<0.001$ & $679(67.2)$ \\
\hline $\begin{array}{l}\text { Days with diuretics administration } \\
\text { during PICU stay }\end{array}$ & $368(72.2)$ & $250(50.0)$ & $<0.001$ & $618(61.2)$ \\
\hline Variable & mean \pm SD/median (IQR) & mean \pm SD/median (IQR) & $\mathrm{p}$-value & mean \pm SD/median (IQR) \\
\hline Age [years] & $9.9 \pm 6.0 / 10.5(12.1)$ & $8.7 \pm 6.0 / 8.3(11.6)$ & NS & $9.3 \pm 6.0 / 10.3(11.4)$ \\
\hline Body mass $[\mathrm{kg}]$ & $36.2 \pm 21.8 / 32.0(34.3)$ & $30.2 \pm 21.8 / 25.0(34.3)$ & NS & $33.4 \pm 21.2 / 29.5(34.6)$ \\
\hline Body length [cm] & $132.4 \pm 35.7 / 138.0(67.8)$ & $120.9 \pm 35.7 / 127.5(75.1)$ & NS & $127.1 \pm 36.4 / 134.5(67.0)$ \\
\hline Number of days in PICU/patient & $20.4 \pm 18.4 / 17.0(21.5)$ & $23.8 \pm 18.4 / 19.0(26.3)$ & NS & $21.9 \pm 19.9 / 17.5(27.0)$ \\
\hline $\begin{array}{l}\text { Percentage of days of mechanical } \\
\text { ventilation }\end{array}$ & $95.5 \pm 16.1 / 100.0(0.0)$ & $37.5 \pm 16.1 / 32.0(70.3)$ & $<0.001^{*}$ & $69.0 \pm 40.7 / 100.0(68.0)$ \\
\hline Number of VPS at CRRT initiation & $1.40 \pm 0.87 / 1.00(1.00)$ & $0.86 \pm 0.87 / 1.00(1.00)$ & 0.039 & $1.15 \pm 0.89 / 1.00(2.00)$ \\
\hline CRP $[\mathrm{mg} / \mathrm{L}]$ at CRRT initiation & $221.9 \pm 146.0 / 238.0(236.8)$ & $111.3 \pm 146.0 / 82.0(149.8)$ & 0.005 & $171.4 \pm 135.8 / 151.0(215.0)$ \\
\hline Total protein $[\mathrm{g} / \mathrm{L}]$ at $\mathrm{CRRT}$ initiation & $53.5 \pm 11.6 / 53.7(16.6)$ & $51.0 \pm 11.6 / 52.0(13.0)$ & NS & $52.4 \pm 11.2 / 53.1(15.1)$ \\
\hline Albumin $[\mathrm{g} / \mathrm{L}]$ at CRRT initiation & $28.5 \pm 7.5 / 29.0(8.9)$ & $27.5 \pm 7.5 / 27.0(12.9)$ & NS & $28.1 \pm 7.4 / 28.0(11.2)$ \\
\hline eGFR $\left[\mathrm{mL} / \mathrm{min} / 1.73 \mathrm{~m}^{2}\right]$ at CRRT initiation & $44.6 \pm 21.4 / 45.6(25.7)$ & $31.7 \pm 21.4 / 28.4(25.8)$ & NS & $38.7 \pm 23.1 / 34.7(32.7)$ \\
\hline Urea [mmol/L] at CRRT initiation & $22.5 \pm 13.1 / 17.0(22.4)$ & $25.9 \pm 13.1 / 21.0(18.3)$ & NS & $24.0 \pm 15.0 / 20.1(20.4)$ \\
\hline UO $[\mathrm{mL} / \mathrm{kg} / \mathrm{h}]$ at CRRT initiation & $0.72 \pm 0.72 / 0.40(0.95)$ & $1.31 \pm 0.72 / 1.20(1.42)$ & 0.048 & $0.99 \pm 1.03 / 0.65(1.30)$ \\
\hline FO\% at CRRT initiation & $45.0 \pm 36.1 / 32.0(32.0)$ & $24.1 \pm 36.1 / 20.0(27.0)$ & 0.024 & $35.5 \pm 31.6 / 27.3(32.5)$ \\
\hline Day of CRRT initiation & $6.6 \pm 7.9 / 3.0(8.3)$ & $4.6 \pm 7.9 / 1.0(5.8)$ & $N S^{*}$ & $5.7 \pm 6.9 / 2.0(8.0)$ \\
\hline
\end{tabular}

*Wilcoxon rank-sum test; ** Yates's modification of the $x^{2}$ test; AKI - acute kidney injury; CRP - C-reactive protein; CRRT - continuous renal replacement therapy; eGFR - estimated glomerular filtration rate; FO\% - fluid overload percentage; Hep-ACG - heparin anticoagulation; MOF - multi-organ failure; PICU - pediatric intensive care unit; QC - citrate flow rate; QD - dialyzate flow rate; QS - supplement flow rate; RCA - regional citrate anticoagulation; SIMV - synchronized intermittent mandatory ventilation; UO - urine output; VPS - vasopressors; SD - standard deviation; IQR - interquartile range; NS - not significant.

in FO\% increased the odds of death by $3 \%$, each $10 \mathrm{mg} / \mathrm{L}$ increase in CRP value increased the odds of death by $7.8 \%$ and each $1 \%$ increase in the percentage of mechanical ventilation increased the odds of death by $6.8 \%$. In the case of the other parameters analyzed, including the volume of UO, eGFR, number of days spent in PICU, and number of hours of CRRT usage, no significant effect on patient survival was demonstrated.

The multivariable logistic regression for 2 input variables, CRP (OR: 1.098; CI 95\%: 1.024-1.178; p = 0.009) and UO (OR: 0.404; CI 95\%: 0.163-1.000; $\mathrm{p}=0.050$ ), indicated that with simultaneous consideration of both factors, each $10 \mathrm{mg} / \mathrm{L}$ increase in CRP with a constant UO value caused an increase in the odds of death by $9.8 \%$, whereas each $1 \mathrm{~mL} / \mathrm{kg} / \mathrm{h}$ increase in UO with a constant CRP value caused a decrease in the odds of death by $59.6 \%$.

Heparin anticoagulation was used significantly more frequently and for significantly longer periods in the deceased children, as compared to the group of survivors (Table 3). As shown in Table 3, the mortality for Hep-ACG was 2.3 times higher than the mortality for RCA (0.66 vs 0.29 ), while the mortality OR demonstrated 4.8 times higher odds of death with the use of Hep-ACG vs RCA (the odds of death for a Hep-ACG and RCA patient were 21/11 = 1.91 
Table 3. Univariate analysis of CRRT-associated factors in the deceased and surviving children in the studied population

\begin{tabular}{|c|c|c|c|c|}
\hline Variable & $\begin{array}{c}\text { Deceased, } \mathrm{n}=25 \\
\mathrm{n}[\%]\end{array}$ & $\begin{array}{c}\text { Surviving, } \mathrm{n}=21 \\
\mathrm{n}[\%]\end{array}$ & p-value & $\begin{array}{c}\text { Total, } n=46 \\
n[\%]\end{array}$ \\
\hline Patients on Hep-ACG/RCA & $21(84.0) / 4(16.0)$ & $11(52.4) / 10(47.6)$ & 0.020 & $32(69.6) / 14(30.4)$ \\
\hline CRRT sessions on Hep-ACG/RCA & $73(56.6) / 56(43.4)$ & $38(41.8) / 53(58.2)$ & 0.030 & $111(50.5) / 109(49.5)$ \\
\hline $\begin{array}{l}\text { Number of hours of CRRT sessions } \\
\text { on Hep-ACG/RCA }\end{array}$ & $3,363(52.2) / 3,076(47.8)$ & $1,800(42.6) / 2,424(57.4)$ & $<0.001$ & $5,163(48.4) / 5,500(51.6)$ \\
\hline Variable & mean \pm SD/median (IQR) & mean $\pm \mathrm{SD} /$ median $(\mathrm{IQR})$ & $p$-value & mean $\pm S D /$ median (IQR) \\
\hline Number of hours of CRRT/patient & $257.6 \pm 319.0 / 154.0(258.5)$ & $201.1 \pm 191.9 / 144.0(218.3)$ & NS & $231.8 \pm 267.3 / 149.0(222.0)$ \\
\hline Filters/patient & $5.2 \pm 5.6 / 4.0(3.0)$ & $4.3 \pm 4.2 / 2.0(3.3)$ & $N S^{*}$ & $4.8 \pm 5.0 / 3.0(3.0)$ \\
\hline $\begin{array}{l}\text { Number of hours of a single filter } \\
\text { work }\end{array}$ & $49.9 \pm 24.2 / 66.0(48.0)$ & $46.4 \pm 26.0 / 59.0(50.8)$ & $N S^{*}$ & $48.5 \pm 25.0 / 62.0(48.0)$ \\
\hline $\mathrm{BFR}[\mathrm{mL} / \mathrm{min} / \mathrm{kg}]$ & $2.57 \pm 1.17 / 2.40(1.55)$ & $2.78 \pm 1.05 / 2.50(1.30)$ & NS & $2.67 \pm 1.11 / 2.50(1.30)$ \\
\hline $\begin{array}{l}\text { Dialysis dose: QD+QS (+QC) } \\
{[\mathrm{mL} / \mathrm{h} / \mathrm{kg}] / \text { patient }}\end{array}$ & $59.47 \pm 24.24 / 50.00(33.96)$ & $59.87 \pm 22.62 / 60.00(21.73)$ & $N S^{*}$ & $59.63 \pm 23.56 / 55.00(31.85)$ \\
\hline UFR $[\mathrm{mL} / \mathrm{h} / \mathrm{kg}]$ & $2.62 \pm 1.63 / 2.40(1.95)$ & $2.40 \pm 1.44 / 2.10(2.10)$ & $N S^{*}$ & $2.53 \pm 1.55 / 2.30(2.00)$ \\
\hline $\mathrm{ACT}[\mathrm{s}]$ & $147.81 \pm 44.60 / 133.63(47.14)$ & $138.43 \pm 20.32 / 136.60(24.61)$ & $\mathrm{NS}^{*}$ & $137.38 \pm 37.54 / 132.00(41.05)$ \\
\hline $\begin{array}{l}\text { Heparin bolus }[\mathrm{mg} / \mathrm{kg}] \text { at the } \\
\text { session start }\end{array}$ & $0.20 \pm 0.12 / 0.18(0.10)$ & $0.21 \pm 0.10 / 0.21(0.09)$ & NS & $0.21 \pm 0.11 / 0.20(0.09)$ \\
\hline Heparin dose [mg/kg/h] & $0.13 \pm 0.09 / 0.11(0.13)$ & $0.17 \pm 0.10 / 0.16(0.08)$ & $0.002^{*}$ & $0.14 \pm 0.10 / 0.13(0.11)$ \\
\hline $\begin{array}{l}\text { Percentage of calcium } \\
\text { compensation }\end{array}$ & $73.44 \pm 22.58 / 70.00$ (30.00) & $70.74 \pm 23.87 / 78.00$ (40.00) & $N S^{*}$ & $72.18 \pm 23.19 / 75.00(35.00)$ \\
\hline Citrate dose & $3.13 \pm 0.24 / 3.10(0.20)$ & $2.98 \pm 0.26 / 3.00(0.30)$ & $<0.001^{*}$ & $3.06 \pm 0.26 / 3.00(0.20)$ \\
\hline CaT/Cal & $1.91 \pm 0.70 / 2.08(0.35)$ & $1.14 \pm 0.93 / 1.00(1.99)$ & $<0.001^{*}$ & $1.52 \pm 0.91 / 1.95(1.17)$ \\
\hline
\end{tabular}

* Wilcoxon rank-sum test; ACT - activated clotting time; BFR - blood flow rate; CaT/Cal - total calcium/ionic calcium index; CRRT - continuous renal replacement therapy; Hep-ACG - heparin anticoagulation; RCA - regional citrate anticoagulation; QC - citrate flow rate; QD - dialyzate flow rate; QS - supplement flow rate; UFR - ultrafiltration rate; SD - standard deviation; IQR - interquartile range; NS - not significant.

Table 4. Multivariable analysis of the impact of fluid overload percentage (FO\%) and applied anticoagulation (ACG) mode on the survival rate

\begin{tabular}{|l|c|c|c|} 
& FO\% - deceased & FO\% - surviving & p-value \\
\hline Hep-ACG & $45.9 \pm 34.5$ & $21.4 \pm 23.8$ & 0.039 \\
\hline RCA & $41.4 \pm 46.4$ & $27.7 \pm 16.8$ & NS \\
\hline p-value & NS & NS & - \\
\hline
\end{tabular}

Data presented as mean \pm standard deviation (SD). ACG - anticoagulation; FO\% - fluid overload percentage; RCA - regional citrate anticoagulation; NS - not significant.

and $4 / 10=0.40$, respectively; thus, the mortality OR was $1.91 / 0.40=4.8)$. Nevertheless, the number of VPS employed at the time of CRRT initiation and the absolute percentage of days with VPS administration during the PICU stay in the Hep-ACG group were significantly higher than in the RCA group (Table 1); thus, it may be concluded that the clinical status of the children treated with Hep-ACG was generally more severe compared to the RCA group, which is a probable reason of the higher mortality. While analyzing whether the employed ACG method might possibly affect the outcome, the multivariable analysis of the effect of FO\% and the applied ACG mode on the survival rate was conducted. The data presented in Table $1 \mathrm{dem}-$ onstrates that no significant difference was found in FO\% values in the children dialyzed using the Hep-ACG vs RCA methods. On the other hand, as shown by the multivariable analysis of the effect of FO\% and the applied ACG mode on survival rate, the only difference in survival was observed in the population of children dialyzed with HepACG, while in the population of the RCA children, no significant difference was seen in mortality (Table 4).

The surviving children required a significantly higher Hep dosage, which means that the amount of the administered Hep was not associated with mortality, while the deceased children received a significantly higher citrate dosage, despite the fact that their $\mathrm{CaT} / \mathrm{CaI}$ ratio was maintained within the normal range (Table 3 ).

The mean and median values of FO\% of the CRRT children since 2009 were high in comparison to the reported percentages in the literature. 8,9 There was no difference in FO\% between the periods 2009-2012 and 2013-2016 (mean \pm SD: $35.1 \pm 34.0$ and median (IQR): 25.0 (35.2) vs mean \pm SD: $35.7 \pm 30.4$ and median (IQR): 28.8 (29.0)). In addition, there was no difference in the mean (2009-2012: $5.5 \pm 5.6$ vs 2013-2016: $5.8 \pm 7.9)$ and median (2009-2012: 3.0 (8.0) vs 2013-2016: 2.0 (8.0)) day of CRRT initiation during the children's hospitalization in PICU over the analyzed period.

There was no difference in the duration of the PICU hospitalization between the CRRT patients $(n=46(1.4 \%)$; mean \pm SD/median (IQR): $21.9 \pm 19.9 / 17.5$ (27.0)) and the rest of the PICU children hospitalized during the same period ( $\mathrm{n}=3,255$; mean $\pm \mathrm{SD} /$ median (IQR): $25.4 \pm 26.2 / 16.0$ (24.0)). However, a significant difference was noted in the mortality between the 2 groups of patients ( $54 \%$ vs $6.5 \%$; $\mathrm{p}<0.001$ ). 


\section{Discussion}

Continuous renal replacement therapy has become the treatment of choice for supporting critically ill patients with AKI ${ }^{17}$ Using a revised AKI definition, recent studies have indicated that up to $10 \%$ of all children admitted to PICUs suffer from some degree of kidney injury. ${ }^{3}$ In accordance with the data from the literature, in the present study, the highest percentage of patients requiring CRRT included children with a primary diagnosis of a hematological/oncological disorder (56.5\%) and children codiagnosed with MOF (67.4\%).

In the literature, several factors have been identified as outcome predictors in the pediatric population requiring CRRT, including late CRRT initiation, hemodynamic instability, specified VPS number and dosage dependency, underlying diseases, low body weight, young age, need for mechanical ventilation, presence of MOF, and FO\%. ${ }^{5,11,18-25}$ In our center, the surviving children required less intensive mechanical respiratory support, were administered a lower number of VPS at CRRT initiation, a lower absolute percentage of days with VPS administration during their PICU stay, and lower CRP values, but they maintained a significantly higher UO value on the day of CRRT initiation, which resulted in the degree of their overhydration at the initiation of CRRT being almost 2-fold lower on average. On the other hand, in the population of non-survivors, MOF as the immediate cause of CRRT initiation was significantly more common. According to the literature, MOF occurs in 30-50\% of children in PICUs and is responsible for a higher percentage of total deaths. ${ }^{26,27}$ In a study by Hayes et al., a diagnosis of MOF was significantly associated with increased mortality, as it was present in $100 \%$ of non-survivors and in $69 \%$ of survivors. ${ }^{22}$ Although in our center no significant differences were observed in the main diagnosis as a factor that might affect mortality, apart from purely nephrological causes, it was nevertheless demonstrated that the probability of death in the cases of concomitant MOF was almost 6 times higher.

Determining the therapeutic dose for CRRT in critically ill children remains a challenge. An analysis of a few randomized studies comparing a conventional vs intensive CRRT dose did not result in any differences in the outcomes (including kidney function and mortality) of PICU patients. ${ }^{8,28}$ In our center, no significant differences were noted in the dialysis dose between the survivors vs nonsurvivors, either.

There are numerous studies which prove that higher fluid accumulation is an independent risk factor of death in CRRT patients even after adjusting for severity of illness. ${ }^{19,21-23}$ The majority of studies indicate that a threshold of $\mathrm{FO} \%$ equal to $20 \%$ is associated with a large increase in mortality. ${ }^{8,9}$ In the literature addressing FO\% in pediatric CRRT, the average FO\% was $16.4 \%$ in survivors and $34 \%$ in non-survivors, and the survival rate was $58 \%$ in those with $\mathrm{FO} \%<20 \%$ as compared to $40 \%$ in those with
FO\% $>20 \%$, despite comparable illness severity scores. ${ }^{11,25}$ According to Sutherland et al., multivariable analysis suggested that each $1 \%$ increase in FO\% was associated with a 3\% increase in mortality OR. ${ }^{21}$ In the current study, the mean values of FO\% showed significant differences between the surviving children (24.1\%) and non-survivors (45.0\%). The cut-off value was assumed as FO\% $=25 \%$, which demonstrated that in the group of children with $\mathrm{FO} \%<25 \%$, the mortality was significantly more than 2-fold lower than in the group of children with FO\% $\geq 25 \%$ (33.3\% vs $67.9 \%$ ). A worsening of the prognosis in the latter population of patients was also demonstrated by the analysis of the Kaplan-Meier curves (Fig. 1). In addition, the univariable logistic regression analysis, as in the study conducted by Sutherland et al., confirmed that each increase in FO\% by $1 \%$ increased the mortality OR by $3 \% .^{21}$

In the current literature there are studies evaluating the efficacy and safety of RCA vs Hep-ACG in pediatric CRRT. These studies have shown that RCA is effective, provides equivalent circuit survival and decreases bleeding as compared to Hep-ACG. ${ }^{29}$ In the studied population, treatment sessions were generally well tolerated by all patients.

Furthermore, in the literature, there are both studies reporting that there is no significant difference in mortality between the RCA (41.3\%) and Hep-ACG (42.7\%) groups, and studies, such as the one by Oudemans-van Straaten et al., proving that RCA appears particularly beneficial, especially after surgery, in sepsis and MOF (suggesting an interference with inflammation), reducing the overall probability of death. ${ }^{13,30-32}$

Although the data collected in our center suggests that the mortality in children dialyzed with Hep-ACG is more than 2-fold higher than the mortality while using the RCA mode, one should take into consideration the fact that the clinical status of children treated with HepACG was in general more severe than the clinical status of

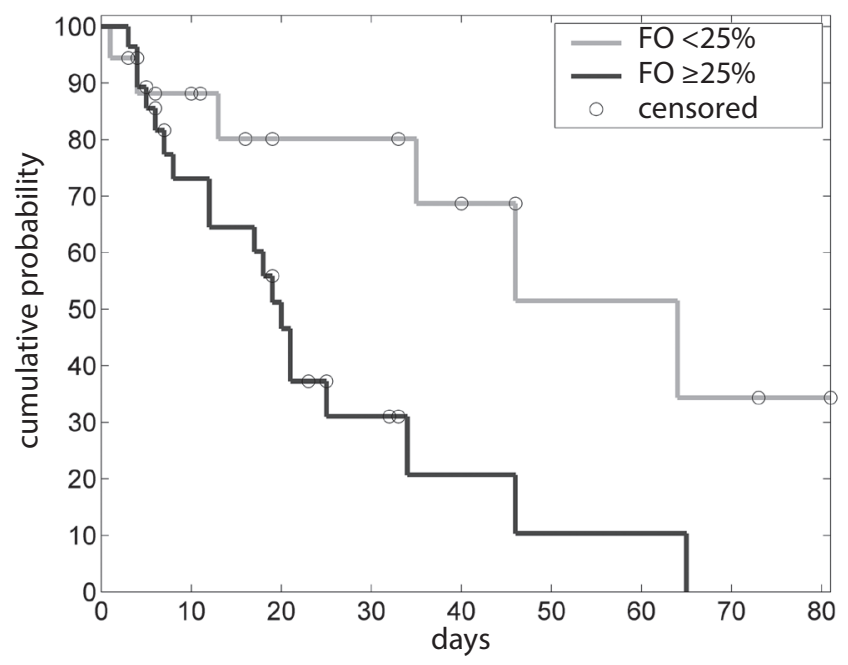

Fig. 1. Comparative Kaplan-Meier analysis for the probability of survival of the continuous renal replacement therapy (CRRT) patients depending on fluid overload percentage (FO\%). The cut-off value of $25 \%$ was statistically significant (Mantel-Cox test: $p=0.012$ ) 
the RCA group, which is undoubtedly the reason of their higher mortality. However, subsequent analyses comparing Hep-ACG with RCA in detail demonstrated that a significant effect on the outcome depending on the values of FO\% occurred only in the group of children dialyzed using Hep-ACG.

A crucial factor in the discrepancy between the mortality of patients treated with the particular modes of ACG might be the fact that RCA in our center has been practically used only since the beginning of 2015 , and that since that time virtually all (14/15) CRRT sessions were performed using this mode of ACG, which means that patients qualified to CRRT during that time were in a better general condition, which may reflect higher vigilance and awareness of the medical staff about the need for CRRT implementation in PICU patients, as well as better acquaintance with the CRRT technique itself.

In our center, CRRT is prescribed and handled by the nephrologists in collaboration with the PICU team. Nevertheless, since the onset of this technique in our center (2009), we have not observed a decrease in the degree of FO\% or a significant difference in the day of initiation of this renal replacement mode.

According to the literature, mortality in PICU patients with secondary AKI requiring CRRT is high, being estimated at $35.6-60 \%$; CRRT is required by about $5 \%$ of all PICU patients. ${ }^{4,18,19,21,22,24,25,33}$ Children with AKI at the time of admission are hospitalized twice as long as patients with normal renal function, while those who develop AKI during the PICU course have a 4-fold increase in the length of stay. ${ }^{3}$ In our center, in the period 2009-2016, contrary to the data from the literature on the subject, the duration of PICU hospitalization did not significantly differ between the children who did and did not require CRRT, but the mortality in the former group was more than 8 -fold higher, which confirmed the reports from the literature describing a poorer prognosis in those patients. ${ }^{9}$

The authors are cognizant of some limitations of the study, as it was a retrospective, observational, single-center study, where interventions could not be standardized. Nevertheless, in the present study, a detailed analysis was performed of the course of PICU hospitalization of all 46 children who were subjected to this treatment technique since the onset of CRRT use in the center. In order to achieve the maximum homogeneity of the analyzed population, in view of the differing nature of AKI in such patients, the analysis did not include patients hospitalized in the cardiac surgery intensive care unit. The study provided a detailed characterization of practically all the factors that might affect the outcome in this population of patients, which is of high importance for future improvements in the quality of care of such patients.

\section{Conclusions}

The mortality of PICU patients who require CRRT is more than 8-fold higher than the mortality of the total PICU population. Coexisting MOF as the immediate cause of CRRT introduction increases the mortality almost 6 times. Apart from the patients' general clinical condition (which is reflected by the CRP values and the need for mechanical ventilation), only FO\% exerts a significant negative effect on the survival of patients requiring CRRT. The mortality of children whose FO\% at the time of CRRT initiation equals or exceeds $25 \%$ is almost 2 -fold higher than the mortality of children whose $\mathrm{FO} \%$ at the time of CRRT initiation does not exceed this value.

\section{References}

1. Barletta GM, Bunchman TE. Acute renal failure in children and infants. Curr Opin Crit Care. 2004;10(6):499-504.

2. Azcan-Arikan A, Zapitelli M, Loftis LL, Washburn KK, Jefferson LS, Goldstein SL. Modified RIFLE criteria in critically ill children with acute renal injury. Kidney Int. 2007;71(10):1028-1035.

3. Schneider J, Khemani R, Grushkin C, Bart R. Serum creatinine as stratified in the RIFLE score for acute kidney injury is associated with mortality and length of stay for children in the pediatric intensive care unit. Crit Care Med. 2010;38(3):933-939.

4. Selewski DT, Cornell TT, Lombel RM, et al. Weight-based determination of fluid overload status and mortality in pediatric intensive care unit patients requiring continuous renal replacement therapy. Intensive Care Med. 2011;37(7):1166-1173.

5. De Galasso L, Emma F, Picca S, Di Nardo M, Rossetti E, Guzzo I. Continuous renal replacement therapy in children: Fluid overload does not always predict mortality. Pediatr Nephrol. 2016;31(4):651-659.

6. Goldstein SL. Overview of pediatric renal replacement therapy in acute kidney injury. Semin Dial. 2009;22(2):180-184.

7. Peng Y, Yuan Z, Li H. Removal of inflammatory cytokines and endotoxin by veno-venous continuous renal replacement therapy for burned patients with sepsis. Burns. 2005;31(5):623-628.

8. Vinsonneau C, Launay EA, Blayau C, et al. Renal replacement therapy in adult and pediatric intensive care: Recommendations by an expert panel from the French Intensive Care Society (SRLF) with the French Society of Anesthesia Intensive Care (SFAR), the French Group for Pediatric Intensive Care Emergencies (GFRUP), the French Dialysis Society (SFD). Ann Intensive Care. 2015;5(1):58.

9. Modem V, Thompson M, Gollhofer D, Dhar AV, Quigley R. Timing of continuous renal replacement therapy and mortality in critically ill children. Crit Care Med. 2014;42(4):943-953.

10. Basu RK, Wheeler DS, Goldstein SL, Doughty L. Acute renal replacement therapy in pediatrics. Int J Nephrol. 2011;2011:785392. doi: 10. 4061/2011/785392

11. Goldstein SL, Currier H, Graf JM, Cosio CC, Brewer ED, Sachdeva R. Outcome in children receiving continuous veno-venous hemofiltration. Pediatrics. 2001;107(6):1309-1312.

12. Goldstein B, Giroir B, Randolph A. International pediatric sepsis consensus conference: Definition for sepsis and organ dysfunction in pediatrics. Pediatr Crit Care Med. 2005;6(1):2-8.

13. Fernández SN, Santiago MJ, López-Herce J, et al. Citrate anticoagulation for CRRT in children: Comparison with heparin. Biomed Res Int. 2014;2014:786301. doi: 10.1155/2014/786301

14. Instrukcja obsługi systemu Prismaflex ${ }^{\circledR}$. Podręcznik operatora. Wersja oprogramowania 8.XX. Order No.: G5036007. 2005-2015. Gambro Lundia $A B$; Lund, Sweden.

15. Tolwani JA, Prendergast MB, Speer RR, Stofan BS, Wille KM. A practical citrate anticoagulation continuous veno-venous hemodiafiltration protocol for metabolic control and high solute clearance. Clin J Am Soc Nephrol. 2006;1(1):79-87.

16. Przykładowe rekomendacje terapeutyczne CRRT z Prismocitrate 18/0. PLMP/MG145/15-0002. Acceptance date: March 2015. Gambro Lundia $A B$; Lund, Sweden. 
17. Sutherland SM, Alexander SR. Continuous renal replacement therapy in children. Pediatr Nephrol. 2012;27(11):2007-2016.

18. Santiago MJ, López-Herce J, Urbano J, et al. Clinical course and mortality risk factors in critically ill children requiring continuous renal replacement therapy. Intensive Care Med. 2010;36(5):843-849.

19. Symons JM, Chua AN, Somers MJG, et al. Demographic characteristics of pediatric continuous renal replacement therapy: A report of the prospective pediatric continuous renal replacement therapy registry. Clin J Am Soc Nephrol. 2007;2(4):732-738.

20. Symons JM, Brophy PD, Gregory MJ, et al. Continuous renal replacement therapy in children up to $10 \mathrm{~kg}$. Am J Kidney Dis. 2003;41(5): 984-989.

21. Sutherland SM, Zappitelli M, Alexander SR, et al. Fluid overload and mortality in children receiving continuous renal replacement therapy: The prospective pediatric continuous renal replacement therapy registry. Am J Kidney Dis. 2010;55(2):316-325.

22. Hayes LW, Oster RA, Tofil NM, Tolwani AJ. Outcomes of critically il children requiring continuous renal replacement therapy. J Crit Care. 2009;24(3):394-400.

23. Foland JA, Fortenberry JD, Warshaw BL, et al. Fluid overload before continuous hemofiltration and survival in critically ill children: A retrospective analysis. Crit Care Med. 2004;32(8):1771-1776.

24. Gillespie RS, Seidel K, Symons JM. Effect of fluid overload and dose of replacement fluid on survival in hemofiltration. Pediatr Nephrol. 2004;19(12):1394-1399.

25. Goldstein SL, Somers MJ, Baum MA, et al. Pediatric patients with multi-organ dysfunction syndrome receiving continuous renal replacement therapy. Kidney Int. 2005;67(2):653-658.
26. Karvellas CJ, Farhat MR, Sajjad I, et al. A comparison of early versus late initiation of renal replacement therapy in critically ill patients with acute kidney injury: A systematic review and meta-analysis. Crit Care. 2011;15(1):R72.

27. Seabra VF, Balk EM, Liangos O, Sosa MA, Cendoroglo M, Jaber BL. Timing of renal replacement therapy initiation in acute renal failure: A meta-analysis. Am J Kidney Dis. 2008;52(2):272-284.

28. Zhongheng Z, Xiao XU, Hongyang Z. Intensive-vs less-intensive-dose continuous renal replacement therapy for the intensive care unitrelated acute kidney injury: A meta-analysis and systematic review. J Crit Care. 2010;25(4):595-600.

29. Davis TK, Neumayr T, Geile K, Doctor A, Hmeil P. Citrate anticoagulation during continuous renal replacement therapy in pediatric critical care. Pediatr Crit Care Med. 2014;15(5):471-485.

30. Liu C, Mao Z, Kang H, Hu J, Zhou F. Regional citrate versus heparin anticoagulation for continuous renal replacement therapy in critically ill patients: A meta-analysis with trial sequential analysis of randomized controlled trials. Crit Care. 2016;20(1):144.

31. Stucker F, Ponte B, Tataw J, et al. Efficacy and safety of citrate-based anticoagulation compared to heparin in patients with acute kidney injury requiring continuous renal replacement therapy: A randomized controlled trial. Crit Care. 2015;18(19):91.

32. Oudemans-van Straaten HM,Bosman RJ, Koopmans M, etal.Citrateanticoagulation for continuous veno-venous hemofiltration. Crit CareMed. 2009;37(2):545-552.

33. Ricci Z, Goldstein SL. Pediatric continuous renal replacement therapy. Contrib Nephrol. 2016;87:121-130. 